\title{
LA EXPERIENCIA DEL TIEMPO EN FUNES EL MEMORIOSO A LA LUZ DE LAS LECCIONES DE FENOMENOLOGÍA DE LA CONCIENCIA INTERNA DEL TIEMPO DE EDMUND HUSSERL
}

Bárbara Bettocchi Chiappina Pontificia Universidad Católica del Perú

El artículo busca presentar las reflexiones acerca de la conciencia interna del tiempo de Edmund Husserl, compiladas en las Lecciones de fenomenología de la conciencia del tiempo de 1928, a la luz del retrato que hace Borges del personaje del cuento Funes el memorioso. Intenta mostrar cómo es que en ambos casos están presentes los mismos cuestionamientos acerca de nuestra experiencia del tiempo y de la persistencia de nuestra identidad en la memoria, y cómo ambas concepciones implican una crítica al atomismo moderno y al empirismo radical. Primero se analizan, por un lado, las descripciones fenomenológicas de Husserl acerca de nuestra percepción de los objetos y, principalmente, del concepto de retención, y por el otro, la conciencia entendida como flujo. Luego, a partir de la caracterización que hace Borges de Funes, el personaje del cuento, y del retrato de su memoria y de la manera como experimenta el mundo a través de la percepción de instantes infinitos, se pretende ilustrar la validez de las concepciones husserlianas arriba mencionadas, dando cuenta de que Funes constituye la representación o puesta en escena de un imposible.

Palabras clave:

Borges, Husserl, tiempo, conciencia, memoria 
And yet, and yet... Negar la sucesión temporal, negar el yo, negar el universo astronómico, son desesperaciones aparentes y consuelos secretos. Nuestro destino (a diferencia del infierno de Swedenborg y del infierno de la mitología tibetana) no es espantoso por irreal; es espantoso porque es irreversible y de hierro. El tiempo es la substancia de que estoy hecho. El tiempo es un río que me arrebata, pero yo soy el río; es un tigre que me destroza, pero yo soy el tigre; es un fuego que me consume, pero yo soy el fuego. El mundo, desgraciadamente, es real; yo, desgraciadamente, soy Borges.

JORGE LUIS BORGES Nueva refutación del tiempo (1946)

Las Lecciones de fenomenología de la conciencia interna del tiempo', publicadas en $1928^{2}$, constituyen una compilación (hecha por Edith Stein) de diversos manuscritos de Husserl sobre la conciencia del tiempo, que datan de los años 1905 a $1910^{3}$. Se trata de escritos de carácter exploratorio, y muchas de las descripciones presentes en ellos constituyen tentativas iniciales que luego se irán transformando y profundizando en trabajos posteriores ${ }^{4}$. No obstante, reflejan las motivaciones y cuestionamientos originales de Husserl sobre la experiencia del tiempo y componen una serie de profundas $y$ originales reflexiones fenomenológicas acerca de ella.

Es justamente a partir de ese tratamiento del tiempo, describiendo fenomenológicamente cómo se da en nosotros esta experiencia, que Husserl lleva a cabo constataciones muy importantes aportando nociones nuevas, como por ejemplo la de retención, por un lado, y la de flujo absoluto de la conciencia,

I Husserl, Edmund, Lecciones de fenomenología de la conciencia del tiempo, traducción, presentación y notas de Agustín Serrano de Haro, Madrid: Trotta, 2002. En adelante, Lecciones.

2 Fueron publicadas por primera vez en el Anuario de Filosofía e Investigación Fenomenológica (tomo IX, pp. 367-498), editadas y prologadas por Martin Heidegger (cf. Serrano de Haro, Agustín, en: Lecciones, pp. 13-14).

3 El título de estas investigaciones alude a la última sección del curso que dio Husserl en el semestre de 1904-1905 en la Universidad de Gotinga sobre Fragmentos capitales de fenomenología y teoría del conocimiento. Pero la compilación realizada por Edith Stein en 1917 recoge también escritos de Husserl entre los años 1905 y 1911 (cf. Serrano de Haro, Agustín, en: ibid., pp. 14-15). 4 "Husserl trabajaba a la búsqueda de la plena clarificación de la problemática, y no le movía una preocupación especial por la coherencia interna, conceptual y terminológica, del cúmulo de textos que no dejaba de crecer" (ibid., p. 16). 
entendido como un continuum, por otro. La retención es un término que introduce Husserl para aproximarse a nuestra vivencia de percepción de una unidad en el presente. Para Husserl, toda percepción constituye una duración y está compuesta del elemento de la retención -o recuerdo primario- que acompaña o va entrelazado a los momentos intencionales de la impresión y de la protención. Es decir, que en toda percepción es necesaria la operación mediante la cual la sucesión de impresiones recientemente pasadas se mantienen en el ahora actual a través de la retención. Así, Husserl llega a la conclusión de que toda unidad de percepción es algo constituido al interior de la conciencia, a través o por medio de la impresión, la retención y la protención. De esta manera, el presente no es concebido como un ahora puntual e instantáneo, sino como un presente extendido.

Pero, además, la retención le sirve a Husserl para explicar cómo aprehendemos el flujo de nuestra propia conciencia como una unidad. Ella solo puede captarse como tal en la retención. Husserl va a hablar aquí de intencionalidad longitudinal de la retención, a través de la cual, en el curso de mis percepciones, puedo también ser consciente de mi propia conciencia constituyente. A diferencia de Descartes, la conciencia absoluta no es objetivable, no se da en la instantaneidad del presente. La conciencia se capta cuando está ya retenida. Me hago consciente del flujo constituyente que acompaña a mis representaciones a través de la retención longitudinal.

Todas estas consideraciones manifiestan una refutación radical por parte de Husserl al atomismo moderno, como el del empirismo, porque muestran claramente que no hay tal cosa como momentos aislados que luego la mente unifica. El presente, en Husserl, está inmerso en un horizonte de retenciones de momentos pasados. Y es recién cuando esos momentos han desaparecido de la conciencia que puedo rememorarlos.

Justamente uno de los elementos que se pueden extraer de la historia de "Funes el memorioso"5, escrita por Jorge Luis Borges en el año 1942 y publicada en 1944 en la colección de cuentos que lleva por título Ficciones $^{6}$, es la crítica

5 Borges, Jorge Luis, "Funes el memorioso" (1944), en: Ficciones, Buenos Aires: Debolsillo, 2011, pp. 123-135.

6 Cf. Nuño, Juan, La filosofía de Borges, México D.F.: FCE, 1986, p. 99. 
al empirismo radical. A pesar de que no se trata aquí de colocar a Borges en la categoría de filósofo o de adjudicarle un motivo o una doctrina filosófica propia, en este relato, como en el caso de gran parte de su obra, se dejan entrever cuestionamientos filosóficos que son ilustrados con una profundidad que solo la literatura puede lograr. Y en "Funes el memorioso" están presentes dos temas que en este trabajo se quieren resaltar, por su relación con los cuestionamientos fenomenológicos husserlianos que acabamos de mencionar líneas arriba: el problema del tiempo y la persistencia de la identidad a través de la memoria. "Borges es un espíritu obsesionado por unos cuantos temas verdaderamente metafísicos: el carácter fantasmagórico, alucinatorio, del mundo; la identidad, a través de la persistencia de la memoria; (...) y, sobre todo, el tiempo, el 'abismal problema del tiempo', con la amenaza de sus repeticiones, de sus regresos, con la nota enfermiza de su ineludible poder que arrastra y devora y quema"7.

La historia de Ireneo Funes llega a nosotros a través del recuerdo de infancia de un hombre y del par de encuentros que tuvo con el personaje. El relato empieza, desde la primera línea, haciendo alusión a la memoria: “Lo recuerdo (yo no tengo derecho a pronunciar ese verbo sagrado, sólo un hombre en la tierra tuvo derecho y ese hombre ha muerto) con una oscura pasionaria en la mano, viéndola como nadie la ha visto, aunque la mirara desde el crepúsculo

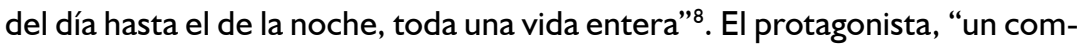
padrito de Fray Bentos, con ciertas incurables limitaciones", había quedado tullido a raíz de una caída de caballo. Pero, además de la parálisis, adquirió a raíz del golpe una memoria desmesurada, casi intolerable. "Nosotros, de un vistazo, percibimos tres copas en una mesa; Funes, todos los vástagos y racimos y frutos que comprende una parra. Sabía las formas de las nubes australes del amanecer del 30 de abril de 1882 y podía compararlas en el recuerdo con las vetas de un libro en pasta española que solo había mirado una vez y con las líneas de la espuma que un remo levantó en el Río Negro la víspera de la acción del Quebracho"10. 
El narrador nos cuenta el encuentro que tuvo con Ireneo cuando va a pedirle que le devuelva unos libros en latín que le había prestado. En esa conversación, Funes le confiesa que posee una memoria infinita, capaz de retener con igual nitidez los mínimos detalles de todas las cosas. "Me dijo: 'Más recuerdos tengo yo solo que los que habrán tenido todos los hombres desde que el mundo es mundo'. Y también: 'Mis sueños son como la vigilia de ustedes'. Y también, hacia el alba: 'Mi memoria, señor, es como un vaciadero de basuras'”|'. Más adelante, Borges nos muestra las maneras en que Funes pretendía describir su realidad, el mundo de sus percepciones, y cómo todas ellas resultaban intentos fallidos por insensatos. El primer proyecto del personaje era el de crear un vocabulario, con una palabra diferente para nominar cada uno de los que forman la serie infinita de los números naturales; el segundo era hacer un catálogo mental de todas las imágenes de su recuerdo. Como el mismo autor lo manifiesta en el relato, ambas empresas dan cuenta del mundo en el que vivía Funes: "Era el solitario y lúcido espectador de un mundo multiforme, instantáneo y casi intolerablemente preciso"|2.

El lenguaje de Ireneo Funes no puede pensarse como tal, y se muestra, de esta manera, como una paradoja. Al reducirse a la mera concreción del instante se desvanece. "Lo que le falta a ese idioma es la capacidad de captar las modificaciones temporales. No es suficiente prescindir de los géneros y atribuir a cada entidad del mundo un nombre individual; para cumplir con las condiciones del mundo de Funes habría que ir más lejos y atribuir un nombre propio a cada entidad del universo en cada instante infinitesimal del tiempo: tarea utópica, como es evidente"|3. La generalización y la abstracción, condiciones necesarias para la simbolización, presuponen la constancia de los objetos en el tiempo, más allá de sus modificaciones. Esto es lo que nos permite captar, y nombrar con el mismo término, al perro de las tres y catorce visto de frente y al perro de las tres y catorce visto de perfil, por ejemplo. De lo contrario, y esto es lo que le sucede al personaje del cuento, solamente podríamos ver

"Ibid.

12 Ibid., p. 134.

13 Bossong, Georg, “La infinitud del lenguaje en la obra de Jorge Luis Borges”, en: Polo García, Victorino (ed.), Borges y la literatura. Textos para un homenaje, Murcia: Universidad de Murcia, 1989, p. 237. 
objetos únicos, que nunca se repetirían, y por lo tanto, no podrían existir para nuestro pensamiento.

De esta manera, no solo queda negada la posibilidad de un lenguaje, sino también la de la percepción misma de cualquier unidad. Y ello porque, al haber solo instantes aislados, dicha vivencia es irrealizable: "A fuerza de solo registrar ideas instantáneas, a modo de fogonazos sucesivos, se rompe el continuum ontológico, siendo entonces imposible respetar la identidad de lo percibido"|4. La posición que retrata Borges aquí es una en la que cada entidad del mundo, en cada instante separado infinitamente del otro, se divide a su vez en una entidad infinitamente más pequeña, y en este camino de concretización se destruye finalmente la posibilidad de captar cualquier objeto.

Funes el memorioso es, como se puede ver, un personaje imposible. Este hombre registraba de manera imborrable todo lo que percibía. Era incapaz de captar la persistencia de un objeto y, por lo tanto, su duración. Funes no poseía la capacidad de rememorar, sino únicamente de percibir instantáneamente cada detalle. Aunque para fines narrativos Funes es presentado de todas maneras como poseyendo cierta capacidad de abstracción, lo que pretende Borges es personificar a un imposible.

Pero veamos, a la luz de las Lecciones de Husserl, por qué Funes el memorioso es un hombre ilusorio. Como dice Landgrebe, las reflexiones de Husserl sobre la conciencia interna del tiempo, presentes en estos escritos, son el resultado de los problemas acerca de la estructura de la percepción exterior con los que se encuentra en sus reflexiones posteriores a las Investigaciones lógicas. Estos cuestionamientos lo llevan a la descripción de las unidades últimas de la corriente de la conciencia a través de las cuales se constituye sintéticamente cualquier objetividad. Así, "también los actos mismos, pues, tenían que ser investigados en vista de sus efectuaciones intencionales, sobre cuya base, luego, son dados a la reflexión como unidades inmanentes"15.

${ }^{14}$ Nuño, Juan, op. cit., p. 102.

${ }^{15}$ Landgrebe, Ludwig, El camino de la fenomenología, traducción de Mario A. Presas, Buenos Aires: Sudamericana, 1968, p. 35. 
Para Husserl (1918-1926), la cuestión del tiempo yace en la constitución de toda objetividad como un volverse-consciente. Code Soto afirma, al analizar el argumento husserliano, que se trata de que "todo objeto es una unidad dotada de una determinada duración que debe ser constituida por la conciencia a través de algún proceso. Toda dación hace referencia a una serie de aspectos temporales que intervienen en su constitución, así como toda dación se sitúa en un determinado tiempo"16. Por lo tanto, el tratamiento del problema de la conciencia del tiempo inmanente no se refiere al tiempo como una magnitud trascendente, objetiva y estable. Más bien, en las reflexiones fenomenológicas de Husserl sobre el tiempo, de lo que se trata es de dejar de lado toda posición referida a la exterioridad para centrarse en el tiempo inmanente del curso de la conciencia misma, se trata de ver cómo se constituye una unidad inmanente como algo que dura ${ }^{17}$. "Lo que nosotros admitimos no es, sin embargo, la existencia de un tiempo del mundo, la existencia de una duración de las cosas, etc., sino el tiempo que aparece, la duración que aparece como tal. (...) Ciertamente que con ello asumimos también un tiempo que existe pero no es el tiempo del mundo de la experiencia, sino el tiempo inmanente del curso de la conciencia"18. Esto no quiere decir que Husserl niegue el tiempo objetivo, el tiempo entendido como magnitud externa, sino que su investigación se dirige más bien a reflexionar sobre el modo como se nos presentan a la conciencia los objetos en tanto temporales y sobre el tiempo que se configura en el flujo de la conciencia originaria ${ }^{19}$.

Para explicar cómo es posible la percepción de un objeto duradero, Husserl utiliza el paradigmático ejemplo de la duración de una melodía. Ella está compuesta de múltiples sonidos que se suceden unos a otros. Pero para que la melodía pueda darse como una unidad es necesario que se produzca una unificación de la sucesión de acontecimientos psíquicos que aprehenden los diversos sonidos. Se trata, pues, de un mismo acto conjunto que capta el discurrir de los sonidos como un todo unitario. "No es, por tanto, que nosotros tengamos los sonidos a la vez, ni que oigamos la melodía debido a la

${ }_{16}$ Code Soto, Francisco, "El problema de la conciencia del tiempo en Edmund Husserl", Tesis doctoral, Universidad de Barcelona, 2004, p. 6.

${ }_{17}$ Cf. Landgrebe, Ludwig, op. cit., p. 36.

18 Lecciones, § I, p. 26.

${ }^{19}$ Cf. Landgrebe, Ludwig, op. cit., p. 37. 
circunstancia de que en el último sonido sigan durando los anteriores, sino que los sonidos forman una unidad sucesiva con un resultado común, la forma de la aprehensión, la cual, naturalmente, no se completa hasta el último sonido”20.

Husserl no se detiene en este punto, sino que además se pregunta cómo hay que entender la aprehensión misma de los objetos temporales. Y dice que la multiplicidad de datos $y$ aprehensiones inmanentes que constituyen a estos objetos discurren, ellos mismos, en una sucesión. Pero aquí también cabe la pregunta por la unificación de estas unidades permanentes en un momento-ahora, para responder a la cual es necesario resolver la cuestión acerca de la constitución del tiempo mismo, de la duración. Este es el camino que sigue, por tanto, el análisis fenomenológico del tiempo. Husserl dirá que "dado que la temporalidad objetiva se constituye en cada caso fenomenológicamente, y dado que sólo mediante esta constitución ella se ofrece ante nosotros apareciendo como objetividad o como momento de una objetividad, un análisis fenomenológico del tiempo no puede aclarar la constitución del tiempo sin considerar la constitución de los objetos temporales" ${ }^{21}$. Estos objetos temporales en sentido especial, como dice Husserl, deben ser entendidos no solo como unidades que están en el tiempo, sino como conteniendo en sí mismos la extensión de tiempo. Se trata de la temporalidad fenomenológica, que se encuentra en toda percepción, y que se conserva como su esencia cuando en el análisis fenomenológico se hace abstracción de todas las trascendencias ${ }^{22}$.

En el § II de las Lecciones, nos dice que el punto-fuente que inaugura la producción de un objeto duradero es la impresión originaria; en ella se marca el ahora puntual del presente. Pero esta conciencia impresional constantemente está siendo relevada por una nueva impresión. Ahora bien, no es que ella desaparezca en la nada, sino que se mantiene modificada en la retención que, a su vez, se adhiere al ahora de la impresión actual. "Pero cuando la conciencia del sonido-ahora, la impresión originaria, pasa a retención, esta misma retención viene a ser por su parte un ahora, algo en existencia

20 Lecciones, § 7, p. 44.

${ }^{21}$ Ibid., § 7, p. 45.

${ }^{22}$ Cf. Ibid., § 7, p. 45. 
actual”23. Una melodía, por ejemplo, que consta de una sucesión de sonidos, es captada como un todo unitario porque los sonidos que han acabado de ser se mantienen vivos, de alguna manera, en el recuerdo fresco de las sucesivas retenciones, que acompañan a la impresión del sonido-ahora. Lo que se retiene son las impresiones modificadas previas, que constantemente van hundiéndose, contrayéndose cada vez más, en el pasado. "Avanzando a lo largo del río o conjuntamente con él, tenemos una serie continua de retenciones que lo son del punto inicial. Pero además cada punto previo de esta serie en calidad de ahora, se escorza a su vez de nuevo en el sentido de la retención. A cada una de estas retenciones se adhiere, pues, una continuidad de modificaciones retencionales, y esta misma continuidad es, de nuevo, un punto de actualidad que se escorza retencionalmente" 24 . Las retenciones más cercanas a la impresión actual serán más claras. Cuanto más distantes estén del momento presente, van desdibujándose. Con esto, Husserl quiere mostrar cómo el objeto duradero puede ser percibido como una unidad. Según sus descripciones, es la unidad de la conciencia retencional la que mantiene sujetas en la conciencia las impresiones discurridas y produce la unidad de conciencia que se refiere al objeto: "El acto constituido, construido a base de conciencia de ahora y conciencia retencional, es percepción adecuada del objeto temporal" 25 .

Por otro lado, Husserl introduce la noción de protención ${ }^{26}$ para referirse a un momento intencional que acompaña a la impresión originaria y a la retención en la percepción: "Todo proceso constituyente está animado por protenciones que constituyen vacíamente lo por venir como tal, y que lo atrapan, lo atraen a cumplimiento" 27 . Así, ocurre que en el acto perceptivo estamos continuamente anticipando lo por venir, que se plenifica cada vez en el presente.

De esta manera, quedan establecidos los caracteres de acto que, junto con los contenidos primarios (las sensaciones), constituyen una percepción: la

\footnotetext{
${ }^{23}$ Ibid., § II, p. $5 \mathrm{I}$.

${ }^{24}$ Ibid., § II, p. 52.

25 Ibid., § 16, p. 60.

${ }^{26}$ De ella nos percatamos en el análisis de la rememoración: "al rememorar un suceso, yo reproduzco también las expectativas con que lo fui viviendo en su momento y que guiaron entonces mi percepción" (ibid., § 24, p.74, nota al pie).
}

27 Ibid., § 24, p. 73. 
impresión originaria, la retención y la protención. Cada vivencia del presente, entonces, comprende un horizonte bilateral y vacío de retenciones y protenciones que están adheridas a la captación del ahora ${ }^{28}$.

Un segundo estrato del horizonte temporal quedará caracterizado por las rememoraciones y las esperas secundarias, que constituyen las presentificaciones (Vergegenwärtigungen). En una reproducción, el "ahora" es un fenómeno ya concluido que es evocado en la conciencia, a diferencia de una percepción, en donde tenemos un acto vivo, algo que se da en persona ${ }^{29}$. La retención, en la percepción, es un ver originario del pasado recién sido. En cambio, en el recuerdo y en la espera secundarios vemos el pasado vicariamente (representativamente). Se trata de distintos tipos de intencionalidad.

Continuando con la profundización de sus análisis de la experiencia del tiempo, Husserl va a ir más lejos y preguntará, además, por la unidad del curso de las aprehensiones mismas. Ello tiene que ver con la unidad de la conciencia. Según Walton, "Las vivencias son lo constituido como objetos temporales inmanentes dentro del curso mismo que es una conciencia absoluta en la medida en que tiene una experiencia de estas unidades que aparecen en ella y no hay una instancia ulterior a la que puede manifestarse" ${ }^{30}$. Husserl va a distinguir entre los objetos temporales, con sus fases, por un lado, y la conciencia del objeto temporal, que a su vez tiene fases. Así, tal como sostiene Walton, "La protoimpresión, la retención y la protención son precisamente estas fases de la conciencia absoluta en las que se tiene una experiencia del objeto inmanente en los modos del ahora, el pasado y el futuro" ${ }^{31}$. Es decir, nos hacemos conscientes del objeto temporal a través de nuestra conciencia, que lo constituye. Pero, ¿cómo captamos nuestra propia conciencia constituyente?

Para resolver la cuestión acerca de cómo captamos la conciencia absoluta o protoconciencia, Husserl recurrirá al análisis de la retención y de su doble intencionalidad. Introducirá la noción de intencionalidad longitudinal de la

${ }^{28}$ Cf. Walton, Roberto, Husserl. Mundo, conciencia y temporalidad, Buenos Aires: Almagesto, 1993, p. 71.

${ }^{29}$ Cf. ibid., p. 75.

30 lbid., p.78.

31 Ibid., p. 79. 
retención como aquella que nos permite captar nuestra propia conciencia, que se manifiesta como conciencia acompañante en el sucederse de nuestras vivencias, y la diferenciará de aquella intencionalidad transversal por medio de la cual nos dirigimos al objeto temporal constituido. Nosotros podemos dirigir la mirada a la unidad inmanente, por ejemplo, un sonido; pero también al flujo que ha acompañado el tránsito de la constitución del sonido, desde el inicio hasta el fin del mismo. De esta manera, es en el recuerdo primario, cuando ya ha discurrido un suceso duradero, que el flujo de conciencia últimamente constituyente (la conciencia absoluta) puede constituirse, a su vez, como una unidad en la conciencia.

Se ha mencionado ya cómo es que la retención es la que posibilita la constitución de la unidad del objeto inmanente, a través del mantenimiento en la memoria de lo recién sido. La retención es, así, conciencia que conserva. Con la intencionalidad transversal puedo dirigir mi atención a la sensación originaria en curso y a las modificaciones retencionales de las sensaciones originarias y de las retenciones pasadas, ofreciéndoseme así la unidad constituida.

Pero además, en cada nuevo ahora, en cada nueva sensación originaria, la retención va retrocediendo en el flujo de conciencia en un constante encorzamiento y va formando parte de una continuidad unitaria de retenciones que se encuentran, como dice Husserl, en «pre-a la vez». "A la vez que la primera retención, hay, empero, un nuevo «ahora», existe una nueva sensación originaria, enlazada en continuidad momentánea con la retención, de suerte que la segunda fase del flujo es sensación originaria del nuevo ahora y retención del previo, y la tercera fase, por su parte, nueva sensación originaria con retención de la segunda originaria y retención de retención de la primera, y así sucesivamente" ${ }^{32}$. Husserl caracteriza a la intencionalidad que recorre el flujo de retenciones como intencionalidad longitudinal. Es con esta última, cuando se dirige la mirada a la sensación originaria en «pre-a la vez» en un determinado punto y a lo retenido en la serie continua de retenciones, que se capta la conciencia pasada en la serie de sus fases, que a su vez prosigue incesantemente como un flujo, siempre con el punto límite de la sensación originaria actual, incorporando continuamente nuevas retenciones y sensaciones originarias.

32 Lecciones, § 39, p. 101. 
Ambas intencionalidades de la retención se entrelazan inseparablemente. "Por la primera de ellas se constituye el tiempo inmanente (...), en el cual hay duración y hay cambio de lo que dura. En la otra intencionalidad se constituye la ordenación quasi-temporal de las fases del flujo, que tiene siempre y necesariamente un punto-ahora fluyente, la fase de actualidad y las series de fases preactuales y postactuales -las que todavía no son actuales-" ${ }^{33}$. En este segundo caso se trata de una temporalidad prefenoménica y se constituye intencionalmente como forma de la conciencia tempoconstituyente, pero que, a su vez, se constituye en la propia conciencia. En el flujo de la conciencia constituyente autoaparece el flujo mismo.

Luego de hacer este recorrido fenomenológico de la experiencia interna del tiempo, volvamos al personaje del cuento de Borges. En Funes queda retratada la figura de la negación del tiempo. Este personaje, que puede pensarse como la caracterización del hiperempírico ${ }^{34}$, también ilustra perfectamente una conciencia fragmentada para la cual solo cabe un tiempo discreto (cartesiano), donde únicamente hay acumulación de instantes que no guardan ninguna conexión entre ellos. Al percibir cada minúsculo detalle y todo con la misma intensidad, el tiempo de Funes se multiplica a la eternidad, como en el caso de la discreción de los números naturales, en donde el camino del I al 2 es infinito.

Tendríamos que decir entonces, si seguimos a Husserl, que la memoria de Funes no era tal, porque para que esta sea posible es necesario el oscurecimiento de las impresiones en el continuum del horizonte temporal. No cabe, pues, otra posibilidad más que darle la razón a este antihéroe cuando se lamenta y dice que su memoria "es como un vaciadero de basuras" 35 , porque sus percepciones vendrían a ser -imaginando la posibilidad de que las tuviera-como elementos concretos e inútiles, incapaces de ser rememoradas y traídas a la conciencia. El propio narrador, al reflexionar sobre la condición de Funes, dice lo siguiente: "Sospecho, sin embargo, que no era muy capaz de pensar.

33 Ibid., § 39, p. 103.

${ }^{34}$ Cf. Nuño, Juan, op. cit., p. 99. No es casualidad, como dice efectivamente Nuño, que Borges haga referencia, en el relato, a Locke: "Locke, en el siglo XVII postuló (y reprobó) un idioma imposible, en el que cada cosa individual, cada piedra, cada pájaro y cada rama tuviera un nombre propio" (Borges, Jorge Luis, op. cit., p. 133). 
Pensar es olvidar diferencias, es generalizar, abstraer. En el abarrotado mundo de Funes no había sino detalles, casi inmediatos" ${ }^{36}$. Y estos detalles que no pueden integrarse debido a que se encuentran alejados en instantes infinitamente separados unos de otros, son como basura, como dice el narrador, porque no sirven para la simbolización.

Así, el memorioso no solo no poseía memoria, sino que ni siquiera puede decirse que pudiera percibir algo, ya que hemos visto que la percepción presupone también el horizonte temporal de despresentación de la retención y la protención, en donde lo conservado y lo anticipado "no es captable como un objeto sino que aparece en los márgenes de la conciencia del objeto"37.

Poco a poco, Borges nos va conduciendo al desmontaje de Funes, a la conclusión de su desvanecimiento, a la constatación de su inexistencia. Así como en el ensayo titulado "Nueva refutación del tiempo" Borges escribe una anacrónica reductio ad absurdum que es la de pretender negar la continuidad, en este relato se puede concluir con Borges, y tomando la terminología de Husserl, que el flujo de la conciencia absoluta es innegable y es la condición de posibilidad de toda constitución y de todo pensamiento, en el sentido de que se trata de una conciencia creadora, porque es en ella que se configura el tiempo inmanente, que es lo que permite toda identidad. Dicha conciencia no se da en el tiempo, entendido este como algo previamente dado, sino que es en ella donde se forma el tiempo mismo y todas las estructuras temporales, y ella misma se constituye como algo que transcurre ${ }^{38}$.

36 Ibid., p. 134.

${ }^{37}$ Walton, Roberto, op. cit., p. 75.

${ }^{38}$ Cf. Landgrebe, Ludwig, op. cit., p. 37. 